\title{
The comparisons of three stapler placement methods for intrathoracic mechanistic circular stapling in Ivor Lewis minimally invasive esophagectomy
}

\author{
Bo Zhang ${ }^{1,2} \wedge$, Zixiang Wu ${ }^{1}$, Qi Wang ${ }^{1}$, Saibo Pan $^{1}$, Lian Wang ${ }^{1}$, Gang Shen ${ }^{1}$, Huiping Chai ${ }^{3}$, Ming Wu ${ }^{1 \wedge}$ \\ ${ }^{1}$ Department of Thoracic Surgery, 2nd Affiliated Hospital, School of Medicine, Zhejiang University, Hangzhou, China; ${ }^{2}$ Department of Thoracic \\ Surgery, Taizhou Hospital, School of Medicine, Zhejiang University, Taizhou, China; ${ }^{3}$ Department of Thoracic Surgery, The First Affiliated Hospital \\ of Anhui Medical University, Hefei, China \\ Contributions: (I) Conception and design: B Zhang, M Wu; (II) Administrative support: M Wu; (III) Provision of study materials or patients: H Chai, \\ M Wu, B Zhang; (IV) Collection and assembly of data: Q Wang, S Pan, L Wang; (V) Data analysis and interpretation: B Zhang, Z Wu, G Shen; (VI) \\ Manuscript writing: All authors; (VII) Final approval of manuscript: All authors. \\ Correspondence to: Ming Wu, MD, PhD. Department of Thoracic Surgery, 2nd Affiliated Hospital, School of Medicine, Zhejiang University, 88 \\ Jiefang Rd, Hangzhou 310009, China. Email: iwuming22@zju.edu.cn; Huiping Chai, MD, PhD. Department of Thoracic Surgery, The First \\ Affiliated Hospital of Anhui Medical University, 218 Jixi Rd, Hefei 230022, China. Email: chaihuipingaysfy@163.com.
}

Background: To analyze the impact of the reversal penetrating technique (RPT) for intrathoracic gastroesophageal mechanical anastomosis on the development of anastomotic complications in Ivor Lewis minimally invasive esophagectomy (ILMIE), and to further identify the risk factors for the development of anastomotic leakage and stricture.

Methods: A retrospective observational study was conducted using the clinical data of 316 patients with esophageal carcinoma (EC) who underwent ILMIE from January 2012 to December 2019. The participants were divided into three groups, namely the RPT group, the transoral Orvil technique (TOT) group, and the purse-string technique (PST) group, according to the different stapler placement methods for intrathoracic mechanistic circular stapling. Multivariate analysis was performed to investigate the association of risk factors with anastomotic leakage and stricture.

Results: There were 154 patients in the RPT group, 78 in the TOT group, and 84 in the PST group for intrathoracic gastroesophageal circular stapling in ILMIE. There were no differences in intraoperative anastomosis-related conditions including conversion of open operations, and lymph nodes harvested between the three groups. However, the mean total operative time and gastroesophageal anastomosis time in the RPT group were significantly shorter than those in the other groups (both $\mathrm{P}<0.05$ ). The rates of anastomotic leakage and stricture showed no statistical differences between the three groups (leakage: $\mathrm{P}=0.875$; stricture: $\mathrm{P}=0.942$ ). Multivariate analysis revealed that the RPT method of anvil placement did not increase the probability of anastomotic leakage [RPT: reference; TOT: odds ratio (OR) 0.422, P=0.341; PST: OR 1.436, $\mathrm{P}=0.645$ ] and stricture (RPT: reference; TOT: OR 0.579, $\mathrm{P}=0.376$; PST: OR 1.195, $\mathrm{P}=0.755$ ).

Conclusions: The RPT method of anvil placement for intrathoracic gastroesophageal circular stapling does not increase the risk of anastomotic complications in ILMIE, but had significantly shorter surgical time and anastomosis time.

Keywords: Esophageal carcinoma (EC); reversal penetrating technique (RPT); Ivor Lewis esophagectomy; minimally invasive esophagectomy

^ ORCID: Bo Zhang, 0000-0002-2336-411X; Ming Wu, 0000-0002-1009-5387. 
Submitted May 18, 2021. Accepted for publication Sep 24, 2021.

doi: 10.21037/jgo-21-322

View this article at: https://dx.doi.org/10.21037/jgo-21-322

\section{Introduction}

Subtotal esophagectomy with radical lymph node dissection remains the mainstream choice for the treatment of esophageal cancer (EC) (1). In recent years, Ivor Lewis minimally invasive esophagectomy (ILMIE) has been increasingly performed in the treatment of middle and lower EC as it prevents complications related to cervical anastomosis and reduces the higher morbidity and mortality of conventional open esophagectomy $(2,3)$.

The mechanistic circular stapled technique is the most frequently implemented approach for intrathoracic esophagogastric anastomosis in ILMIE (4). It requires insertion of the anvil into the proximal esophagus stump and anastomosis of the anvil rod with the stapler shaft. However, the appropriate placement of the anvil into the esophageal stump is a challenging step in the thoracoscopic operation (5). Depending on the manner of anvil introduction, the main methods of circular stapled intrathoracic anastomoses include a transoral Orvil technique (TOT) and a hand-sewn purse-string technique (PST). In recent years, the reversal penetrating technique (RPT), a modified anastomotic technique for ILMIE, has been reported to be a simple and effective approach, and its practice experience has been accumulating in some centers (5-7). However, no study has yet compared RPT and the former two methods in intrathoracic anastomoses for esophagogastrostomy.

Anastomotic failure in the form of stricture or leakage is common and critical $(8,9)$. Anastomotic leakage is the main cause of postoperative morbidity, mortality, and prolonged hospitalization (10). Anastomotic stricture requires serial anastomotic dilatation and significantly impairs long-term quality of life. The anastomotic technique might be one major factor that influences anastomotic complications (11). Therefore, in this study, we retrospectively analyzed the impact of RPT on the incidence of anastomotic complications, and we also further identified the risk factors for the development of anastomotic leakage and stricture following ILMIE. We present the following article in accordance with the STROBE reporting checklist (available at https://dx.doi.org/10.21037/jgo-21-322).

\section{Methods}

\section{Patients}

The clinical data of the patients receiving total laparoscopic and thoracoscopic Ivor Lewis esophagectomy with intrathoracic esophagogastric mechanistic circular stapled anastomosis from Jan 2012 to Dec 2019 in our institution were collected. All patients were diagnosed with EC by gastroscopy and had received overall preoperative assessment including clinical symptoms, physical examination, and auxiliary laboratory and imaging examinations, etc. Cardiopulmonary function was evaluated by pulmonary function, electrocardiogram, color Doppler echocardiography, and blood gas analysis. All patients underwent esophageal ultrasonography, supraclavicular lymph node ultrasonography, enhanced thoracoabdominal CT, cranial magnetic resonance imaging, or PET/CT for clinical staging. After surgery, all patients were staged according to the 8th edition staging system of the American Joint Committee on Cancer (AJCC) (12). We excluded patients with the upper thoracic esophageal carcinoma. The participants were divided into three groups, namely the RPT, TOT, and PST group according to the different stapler placement methods for intrathoracic mechanistic circular stapling. Clinical data were obtained and retrospectively analyzed from the electronic medical record database, including demographic characteristics, pathological data, anastomosis related conditions, and anastomosis complications, among others. This study was performed in accordance with the principles of the Declaration of Helsinki (as revised in 2013). This research project was approved by the Ethics Committee of the 2nd Affiliated Hospital, School of Medicine, Zhejiang University with approval number 2021-0802. Due to the retrospective design of the study, the local ethics committee confirmed that informed consent was not necessary from participants.

\section{Surgery methods}

ILMIE with intrathoracic mechanistic circular esophagogastric anastomosis, which was performed similarly to procedures 

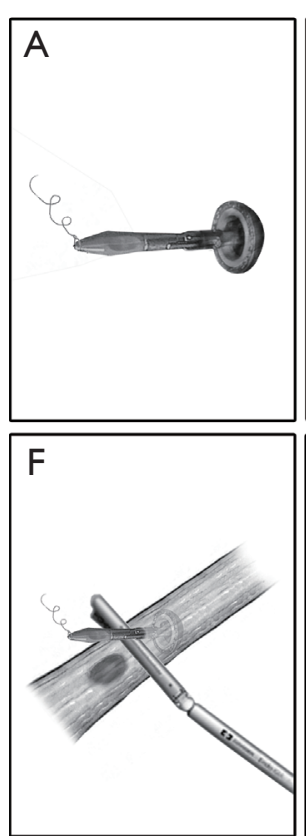
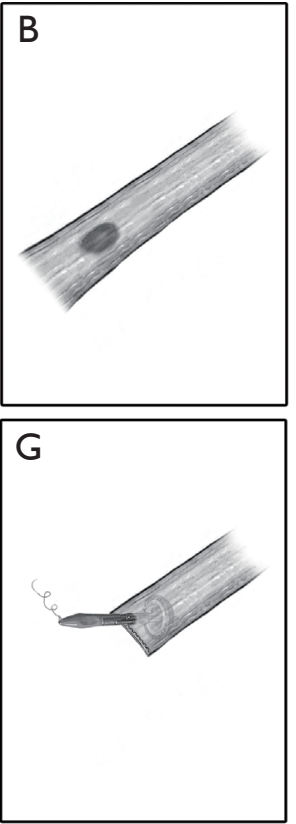
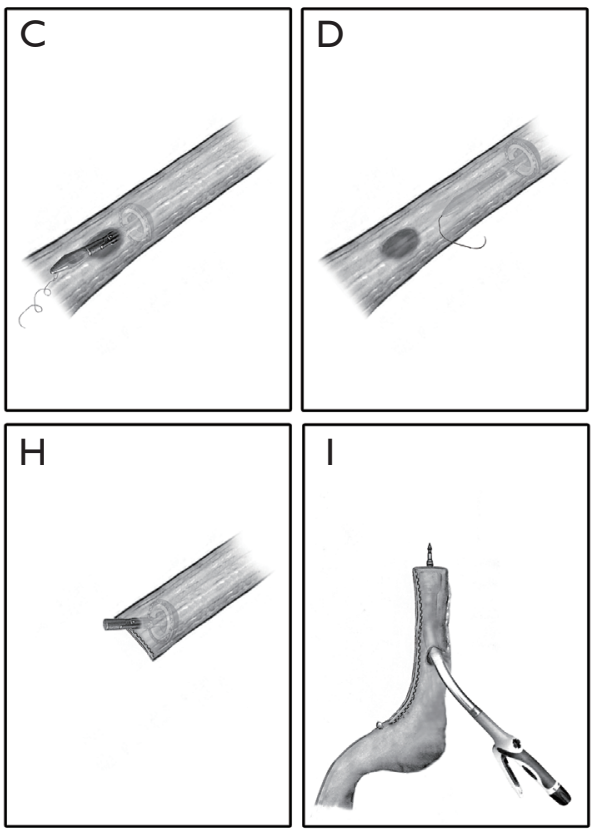

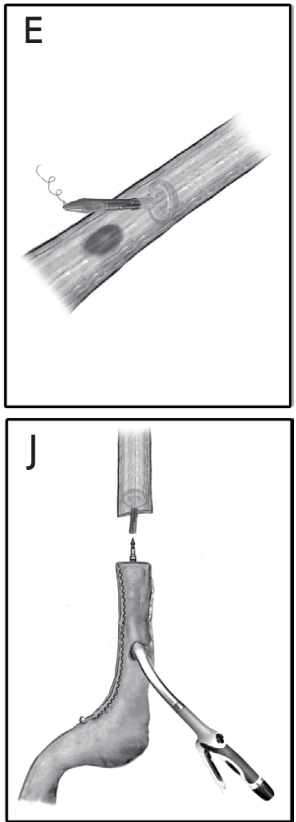

Figure 1 The main operative steps of the reverse penetrating technique in Ivor Lewis minimally invasive esophagectomy. (I) Establishment of an anvil set (A). (II) Placement of the anvil in the esophagus: making a longitudinal incision on the esophageal anterior wall (B); inserting the anvil set into the esophageal lumen (C); penetrating reversely the esophageal wall with a stitch (D) and pulling out the anvil rod (E); transecting the proximal esophagus with the linear stapler $(\mathrm{F})$; detaching the ancillary trocar from the anvil rod and obtaining the anvil placement $(\mathrm{G}, \mathrm{H})$. (III) Completion of intrathoracic anastomosis: sending the shaft of the circular stapler into the gastric conduit through gastrostomy (I) and docking with the anvil to achieve anastomosis (J).

described in previous literature $(5,13)$, was conducted when the patient was under combined general-epidural anesthesia and double-lumen endotracheal intubation. A gastric conduit was created in most cases. The intrathoracic esophagogastric anastomosis was performed using a circular stapling device. The methods of anvil placement included the TOT, hand-sewn PST, and RPT.

\section{TOT (14)}

Esophageal dissection was performed with a linear stapler. Then, the Orvil anvil (DST Series EEA Orvil Device; Covidien) was attached to an orogastric tube, which was fully lubricated and inserted transorally by the anesthesiologist under laryngoscopy. The tube passed out through an incision created at the tip of the esophageal stump and the anvil was sent to and fixed at the predetermined position. The circular stapler was placed into the gastric conduit through gastrostomy. Then, the circular stapler was docked with the anvil to complete the intrathoracic esophagogastric anastomosis.

\section{The hand-sewn PST $(15,16)$}

A 3-0 suture was used to create a hand-sewn purse string through the muscular layer of the esophagus at least $5 \mathrm{~cm}$ proximal to the tumor. A transverse incision was made $2 \mathrm{~cm}$ distal to the purse-string suture of the esophagus and the anvil was inserted and fixed by tightening the purse string. Then, the esophagus was transected. The gastric conduit was pulled out from the abdominal cavity into the thoracic cavity and the circular stapler was introduced into the gastric conduit to dork with the anvil to construct the intrathoracic anastomosis. The bottom opening of the gastric conduit was closed with the linear stapler.

\section{RPT $(5,17)$}

The main operative steps of ILMIE are shown in Figure 1. A 2-0 prolene suture stitch was linked to the tip of the ancillary rod with a knot. A longitudinal incision was made more than $3.0 \mathrm{~cm}$ above the tumor margin on the esophageal wall. The anvil with the suture was inserted into the esophagus lumen through the incision. Then, 
the suture penetrated the esophagus wall reversely at the predetermined anastomosis position, roughly $5.0 \mathrm{~cm}$ above the tumor margin. The suture was pulled to guide the penetration and positioning of the anvil on the esophagus wall. Then, the linear stapler was used to transect the esophagus and obtain the sample. The circular stapler was placed in the gastric conduit through gastrostomy and docked with the anvil to complete the intrathoracic anastomosis. The bottom opening of the gastric conduit was sutured with absorbable line or closed with the linear stapler.

\section{Postoperative management}

All patients were treated with regular fast, gastrointestinal decompression, analgesia, antibiotics, and antacid therapy. Parenteral nutritional support started $24 \mathrm{~h}$ after the operation. The drainage tube was removed on the $3 \mathrm{rd}$ postoperative day. Upper gastrointestinal radiography with iodized oil and oral administration of methylene blue dilution were given on the 7 th postoperative day to evaluate the integrity of the anastomosis. A fluid diet was resumed on the 6th postoperative day, and a semifluid diet commenced on the $8^{\text {th }}$ day. Patients with no manifestations of discomfort were discharged from the hospital on the $9-10^{\text {th }}$ postoperative day.

\section{Perioperative variables and surgical complications}

Clinical data were obtained and retrospectively analyzed from the electronic medical record database, including patient demographic characteristics, tumor features, anastomosis related conditions, and anastomosis complications, among others. The following anastomosisrelated conditions were recorded: conversion rate, anastomosis position, surgical time, and number of lymph nodes harvested. The postoperative anastomosis complications included the following: anastomosis leakage, stricture, esophagotracheal leakage, and reflux esophagitis. Anastomosis leakage was defined as blue fluid outflowing from the drainage tube, or contrast leakage from the site of intrathoracic anastomosis or clinical suspected leakage requiring alteration of therapy. In our study, we further differentiated minor leakage and major leakage on the basis of the classification system of the Esophagectomy Complications Consensus Group (ECCG) (18). Minor leakage corresponds to type I leakage in the ECCG classification, which refers to leakage associated with no or minor clinical presentation and necessitating no additional intervention (19). Major leakage corresponds to type II and III leakage in the ECCG classification, which refers to leakage presenting signs of inflammation and necessitating related intervention (19). Anastomosis stricture was defined as the development of a feeding obstruction or anastomosis narrowing less than $1 \mathrm{~cm}$ under endoscopy or gastrointestinal radiograph and dysphagia requiring at least 1 endoscopic dilatation to relieve the symptom (20).

\section{Statistical analysis}

All statistical analyses were performed with SPSS 22.0 (SPSS Inc., Chicago, IL). All tests were two-sided with a significance level of 0.05 . The continuous variables were shown as means \pm standard deviation (SD) and compared by ANOVA or the Kruskal-Wallis test between more than two groups. The categorical variables were focused on frequencies and proportions, and compared by Chi-square or Fisher's exact tests between groups. The non-parametric test was used if the one-way ordered $\mathrm{R} \times \mathrm{C}$ list (grade data) did not meet the chi-square test premise. Logistic regression models were used to analyze the influence of clinical and pathological factors on anastomotic leakage and stricture. Univariate analysis was used to determine the correlation between factors and anastomotic leakage or stricture. Candidate variables that showed a univariate relationship with outcome or that were considered clinically relevant were included in the multivariate logistic regression analysis to generate the multivariate logistic regression model. Additionally, 95\% confidence intervals (CI) and odds ratio (OR) were calculated.

\section{Results}

A total of 316 patients with EC receiving ILMIE were included in the present analysis. There were 154 patients in the RPT group, 78 in the TOT group, and 84 in the PST group. The clinical characteristics of the patients in each study group are listed in Table 1. Except for the method of anvil placement, the perioperative treatment strategy was the same for all the included patients. The patients of the three groups were not statistically different with respect to demographics, comorbidities, preoperative therapy, tumor location, or 30-day mortality (all $\mathrm{P}>0.05$ ).

The anastomosis-related conditions in esophagectomy are summarized in Table 2. The total conversion rate, the rate of conversion due to anastomosis, the number of total 
Table 1 Characteristics of patients and tumors

\begin{tabular}{|c|c|c|c|c|c|}
\hline Characteristics & RPT group (N=154) & TOT group (N=78) & PST group (N=84) & $\mathrm{F} / \chi^{2}$ & $P$ \\
\hline Female:male, $\mathrm{n}$ & $20: 134$ & $18: 60$ & $12: 72$ & 4.160 & 0.125 \\
\hline BMI (mean, kg/m²) & $21.55 \pm 2.70$ & $20.88 \pm 2.31$ & $21.49 \pm 3.11$ & 1.685 & 0.187 \\
\hline \multicolumn{6}{|l|}{ Co-morbidity, n (\%) } \\
\hline Diabetes & $19(12.34)$ & $8(10.26)$ & $10(11.90)$ & 0.221 & 0.895 \\
\hline COPD & $11(7.14)$ & $5(6.41)$ & $6(7.14)$ & 0.049 & 0.976 \\
\hline Previous chest or abdominal surgery & $7(4.55)$ & $1(1.28)$ & $2(2.38)$ & 1.628 & $0.456^{*}$ \\
\hline Smoking history, n (\%) & $88(57.14)$ & $42(53.85)$ & $46(54.76)$ & 0.269 & 0.874 \\
\hline Middle third & $66(42.86)$ & $30(38.46)$ & $40(47.62)$ & & \\
\hline Lower third & $88(57.14)$ & $48(61.54)$ & $44(52.38)$ & & \\
\hline pT, stage, n (\%) & & & & 8.969 & $0.011^{\#}$ \\
\hline $\mathrm{T} 1$ & $34(22.08)$ & $10(12.82)$ & $18(21.43)$ & & \\
\hline T2 & $24(15.58)$ & $6(7.69)$ & $18(21.43)$ & & \\
\hline T3 & $94(61.04)$ & 60 (76.92) & $47(55.95)$ & & \\
\hline $\mathrm{T} 4$ & $2(1.30)$ & $2(2.56)$ & $1(1.19)$ & & \\
\hline pN, stage, n (\%) & & & & 10.102 & $0.006^{\#}$ \\
\hline In-hospital/30-day mortality, n (\%) & $3(1.95)$ & $1(1.28)$ & $1(1.19)$ & 0.325 & $1.000^{*}$ \\
\hline
\end{tabular}

lymph nodes harvested, and the number of mediastinal lymph nodes harvested were not significantly different between groups (all $\mathrm{P}>0.05$ ). However, the total surgical time and anastomosis time among the three groups were statistically significant (both $\mathrm{P}<0.05$ ). Furthermore, multiple comparisons with Dunnett's test (TOT vs. RPT and PST vs. RPT) showed that the total surgical time and anastomosis time in the RPT group were significantly shorter than those in both the PST group and TOT group (all $\mathrm{P}<0.05$ ).
Table 3 shows the postoperative anastomotic complications in all patients, as well as the differences in anastomotic complications among the RPT, TOT, and PST groups. Anastomotic leakage occurred in 25 patients (7.91\%), of which 19 cases had minor anastomotic leakage and 6 cases had major leakage. However, none of the anastomotic leakage rates, regardless of the total rate, minor anastomotic leakage rate, or major anastomotic leakage rate, were significantly different between the 3 
Table 2 Anastomosis-related conditions

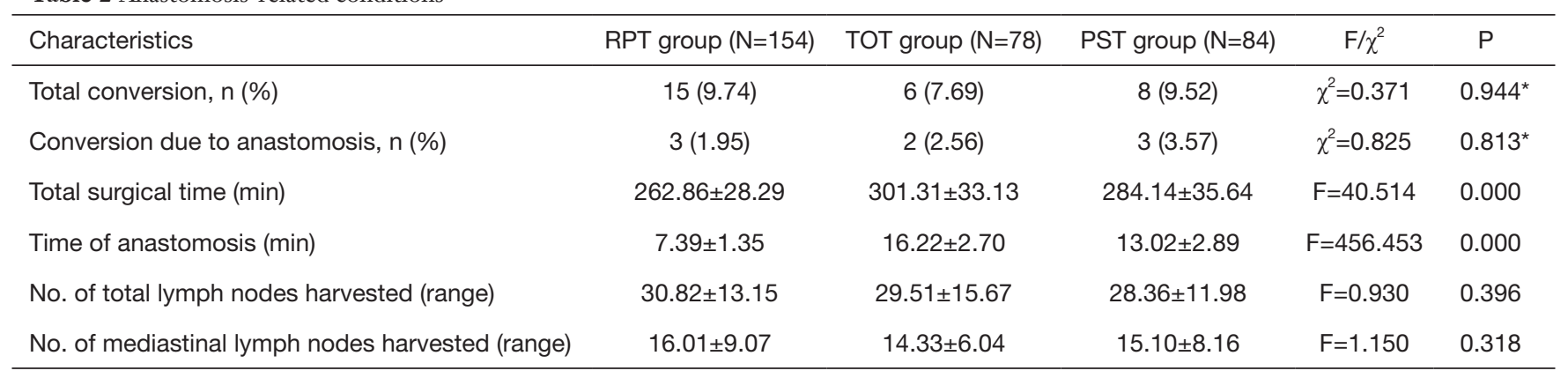

*, calculation by Fisher's exact test. RPT, reversal penetrating technique; PST, purse-string stapled anastomotic technique; TOT, transoral

Orvil stapled anastomotic technique.

Table 3 Anastomosis complications

\begin{tabular}{|c|c|c|c|c|c|c|}
\hline Anastomotic complications & RPT group ( $N=154)$ & TOT group $(\mathrm{N}=78)$ & PST group $(\mathrm{N}=84)$ & Total $(\mathrm{N}=316)$ & $\chi^{2}$ & $\mathrm{P}$ \\
\hline \multicolumn{7}{|l|}{ Anastomotic leakage } \\
\hline Minor (type I), n (\%) & $8(5.19)$ & $6(7.69)$ & $5(5.95)$ & $19(6.01)$ & 0.572 & 0.751 \\
\hline Major (type II, type III), n (\%) & $3(1.95)$ & $1(1.28)$ & $2(2.38)$ & $6(1.90)$ & 0.266 & 0.875 \\
\hline Total leakage, n (\%) & $11(7.14)$ & $7(8.97)$ & $7(8.33)$ & $25(7.91)$ & 0.266 & 0.875 \\
\hline Anastomotic stricture, $\mathrm{n}(\%)$ & $23(14.94)$ & $13(16.67)$ & $13(15.48)$ & $49(15.51)$ & 0.119 & 0.942 \\
\hline Reflux esophagitis, n (\%) & $68(44.16)$ & $34(43.59)$ & $34(40.48)$ & $136(43.04)$ & 0.313 & 0.855 \\
\hline $\begin{array}{l}\text { Frequent dependence on anti-reflux } \\
\text { medication, } \mathrm{n}(\%)\end{array}$ & $45(29.22)$ & $22(32.05)$ & 26 (30.95) & $93(29.43)$ & 0.153 & 0.926 \\
\hline
\end{tabular}

*, calculation by Fisher's exact test. RPT, reversal penetrating technique; PST, purse-string stapled anastomotic technique; TOT, transoral Orvil stapled anastomotic technique.

experimental groups (all $\mathrm{P}>0.05$ ). All included patients received postoperative endoscopic evaluation. In total, 49 patients $(15.51 \%)$ presented with anastomotic stricture in all groups (Table 3). However, the stricture rates among the RPT, TOT, and PST groups were not significantly different $(\mathrm{P}>0.05)$. Furthermore, no significant difference among the three groups was noted in esophagotracheal leakage, reflux esophagitis (including anastomotic inflammation), and frequent dependence on anti-reflux medication (all $\mathrm{P}>0.05$ ).

The results of univariate and multivariate analyses for the prediction of anastomotic leakage and stricture are listed in Tables 4 and 5, respectively. The multivariate logistic regression analyses using an enter model revealed that tumor location, and neoadjuvant therapy predicted anastomotic leakage, rather than the methods of anvil placement. Moreover, anastomotic stricture was significantly influenced by the presence of BMI, smoking history, conversion, and neoadjuvant therapy rather than by the methods of anvil placement.

\section{Discussion}

The RPT, a modified method of stapler placement applied in ILMIE, has been reported to be a simple and effective approach, and its practice experience has been accumulating in some centers in the past few years $(4,21)$. We performed this retrospective study to investigate the influence of the RPT compared with the PST and TOT on anastomotic leakage and stricture. We also performed multivariate analysis to analyze the influence of risk factors on anastomotic leakage and stricture in patients undergoing ILMIE.

Our analysis results revealed that the surgery time and anastomosis time of the RPT group were significantly 
Table 4 Univariate and multivariate analyses for anastomotic leakage

\begin{tabular}{|c|c|c|c|c|c|c|c|c|}
\hline Variables & Total No. & No. of $A L(\%)$ & \multicolumn{3}{|c|}{ Univariate analysis } & \multicolumn{3}{|c|}{ Multivariate analysis } \\
\hline Age (year) & & & 1.202 & $0.528-2.741$ & 0.661 & 1.698 & $0.515-5.594$ & 0.384 \\
\hline$<60$ & 126 & $11(8.73)$ & & & & & & \\
\hline$\geq 60$ & 190 & $14(7.37)$ & & & & & & \\
\hline Male & 266 & $22(8.27)$ & & & & & & \\
\hline Female & 50 & $3(6.00)$ & & & & & & \\
\hline \multicolumn{9}{|l|}{ BMI $\left(\mathrm{kg} / \mathrm{m}^{2}\right)$} \\
\hline$\leq 18.5$ & 38 & $10(26.32)$ & & & & & & \\
\hline Smoking history & & & 0.790 & $0.338-1.848$ & 0.587 & 1.623 & $0.460-5.728$ & 0.451 \\
\hline Yes & 186 & $16(8.60)$ & & & & & & \\
\hline No & 130 & 9 (6.92) & & & & & & \\
\hline Alcohol history & & & 0.516 & $0.224-1.188$ & 0.120 & 0.417 & $0.118-1.472$ & 0.174 \\
\hline Yes & 142 & $15(10.56)$ & & & & & & \\
\hline No & 174 & $10(5.75)$ & & & & & & \\
\hline Tumor location & & & 2.107 & $0.916-4.850$ & 0.080 & 3.458 & $1.123-10.645$ & 0.031 \\
\hline Middle third & 136 & 15 (11.03) & & & & & & \\
\hline Conversion & & & 0.360 & $0.124-1.043$ & 0.060 & 0.524 & $0.119-2.315$ & 0.394 \\
\hline Yes & 29 & $5(17.24)$ & & & & & & \\
\hline No & 287 & $20(6.97)$ & & & & & & \\
\hline Time of anastomosis & 316 & 25 & 0.955 & $0.873-1.044$ & 0.310 & 0.906 & $0.737-1.114$ & 0.350 \\
\hline Total surgical time & 316 & 25 & 0.991 & $0.980-1.003$ & 0.125 & 0.985 & $0.968-1.003$ & 0.102 \\
\hline \multicolumn{9}{|l|}{ T stage } \\
\hline $\mathrm{T} 1$ & 62 & $6(9.68)$ & & & & & & \\
\hline $\mathrm{T} 2$ & 48 & $2(4.17)$ & 2.333 & $0.223-24.405$ & $0.479^{b}$ & 1.979 & $0.070-55.750$ & $0.688^{b}$ \\
\hline T3 & 201 & $16(7.96)$ & 5.750 & $0.423-78.104$ & $0.189^{b}$ & 6.493 & $0.182-231.976$ & $0.305^{b}$ \\
\hline $\mathrm{T} 4$ & 5 & $1(20.00)$ & 2.891 & $0.305-27.427$ & $0.355^{\mathrm{b}}$ & 1.426 & $0.061-33.244$ & $0.825^{\mathrm{b}}$ \\
\hline
\end{tabular}

Table 4 (continued) 
Table 4 (continued)

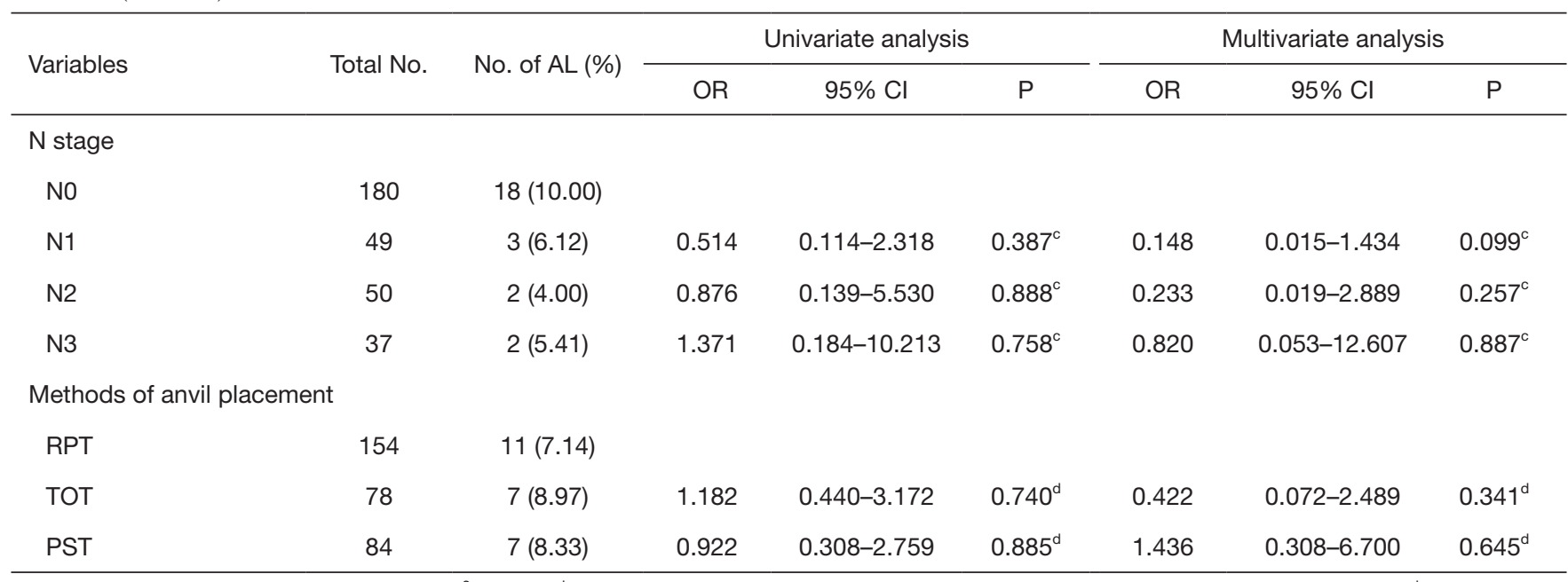

${ }^{\mathrm{a}}$, compared with the $\mathrm{BMI} \leq 18.5 \mathrm{~kg} / \mathrm{m}^{2}$ group; ${ }^{\mathrm{b}}$, compared with the I stage group; ${ }^{\mathrm{c}}$, compared with the $\mathrm{N}$ stage group; ${ }^{\mathrm{d}}$, compared with the RPT group. AL, anastomotic leakage; BMI, body mass index; RPT, reversal penetrating technique; PST, purse-string stapled anastomotic technique; TOT, transoral Orvil stapled anastomotic technique; OR, odds ratio; Cl, confidence interval.

Table 5 Univariate and multivariate analyses for anastomotic stricture

\begin{tabular}{|c|c|c|c|c|c|c|c|c|}
\hline Variables & Patient No. & No. of AS (\%) & \multicolumn{3}{|c|}{ Univariate analysis } & \multicolumn{3}{|c|}{ Multivariate analysis } \\
\hline Age (years) & & & 1.277 & $0.691-2.361$ & 0.435 & 2.023 & $0.923-4.434$ & 0.078 \\
\hline$<60$ & 126 & $22(17.46)$ & & & & & & \\
\hline$\geq 60$ & 190 & $27(14.21)$ & & & & & & \\
\hline Male & 266 & $43(16.17)$ & & & & & & \\
\hline Female & 50 & $6(12.00)$ & & & & & & \\
\hline \multicolumn{9}{|l|}{ BMI $\left(\mathrm{kg} / \mathrm{m}^{2}\right)$} \\
\hline$\leq 18.5$ & 38 & $18(78.26)$ & & & & & & \\
\hline Smoking history & & & 1.458 & $0.791-2.687$ & 0.227 & 3.336 & $1.376-8.086$ & 0.008 \\
\hline Yes & 186 & $25(13.44)$ & & & & & & \\
\hline No & 130 & $24(18.46)$ & & & & & & \\
\hline Alcohol history & & & 0.680 & $0.369-1.252$ & 0.215 & 0.597 & $0.255-1.401$ & 0.236 \\
\hline Yes & 142 & 26 (14.94) & & & & & & \\
\hline No & 174 & $23(16.20)$ & & & & & & \\
\hline Tumor location & & & 1.094 & $0.592-2.019$ & 0.775 & 1.406 & $0.668-2.957$ & 0.369 \\
\hline Middle third & 136 & $22(16.18)$ & & & & & & \\
\hline
\end{tabular}

Table 5 (continued) 
Table 5 (continued)

\begin{tabular}{|c|c|c|c|c|c|c|c|c|}
\hline Variables & Patient No. & No. of AS (\%) & \multicolumn{3}{|c|}{ Univariate analysis } & \multicolumn{3}{|c|}{ Multivariate analysis } \\
\hline Lower third & 180 & $27(15.00)$ & & & & & & \\
\hline Neoadjuvant therapy & & & 0.299 & $0.129-0.690$ & 0.005 & 0.170 & $0.058-0.496$ & 0.001 \\
\hline Yes & 29 & $10(34.48)$ & & & & & & \\
\hline Conversion & & & 0.360 & $0.153-0.846$ & 0.019 & 0.288 & $0.093-0.887$ & 0.030 \\
\hline Yes & 29 & $9(31.03)$ & & & & & & \\
\hline No & 287 & $40(13.94)$ & & & & & & \\
\hline Time of anastomosis & 316 & 25 & 0.977 & $0.912-1.046$ & 0.505 & 0.922 & $0.791-1.075$ & 0.301 \\
\hline $\mathrm{T} 1$ & 62 & $10(16.13)$ & & & & & & \\
\hline $\mathrm{T} 2$ & 48 & $6(12.50)$ & 1.300 & $0.131-12.882$ & $0.823^{b}$ & 0.997 & $0.047-21.297$ & $0.999^{b}$ \\
\hline T3 & 201 & $32(15.92)$ & 1.750 & $0.167-18.393$ & $0.641^{b}$ & 1.999 & $0.090-44.285$ & $0.661^{b}$ \\
\hline $\mathrm{T} 4$ & 5 & $1(20.00)$ & 1.320 & $0.143-12.201$ & $0.807^{b}$ & 0.859 & $0.046-16.223$ & $0.919^{b}$ \\
\hline \multicolumn{9}{|l|}{$\mathrm{N}$ stage } \\
\hline No & 180 & $33(18.33)$ & & & & & & \\
\hline N1 & 49 & $6(12.24)$ & 0.696 & $0.252-1.921$ & $0.484^{c}$ & 0.430 & $0.111-1.666$ & $0.222^{\circ}$ \\
\hline N2 & 50 & $5(10.00)$ & 1.120 & $0.314-3.995$ & $0.862^{c}$ & 0.723 & $0.144-3.636$ & $0.694^{\circ}$ \\
\hline
\end{tabular}

${ }^{a}$, compared with the BMI $\leq 18.5 \mathrm{~kg} / \mathrm{m}^{2}$ group; ${ }^{b}$, compared with the I stage group; ${ }^{\text {, }}$ compared with the $\mathrm{N}$ stage group; ${ }^{\mathrm{d}}$, compared with the RPT group. AS, anastomosis stricture; BMI, body mass index; RPT, reversal penetrating technique; PST, purse-string stapled anastomotic technique; TOT, transoral Orvil stapled anastomotic technique; OR, odds ratio; $\mathrm{Cl}$, confidence interval.

shorter than those of the TOT and PST group. However, other anastomosis-related conditions, including conversion rate and number of lymph nodes dissected, and anastomosis complications, including anastomosis leakage and stricture of the RPT group, were not significantly different from those in the TOT and PST groups.

The shorter surgery time and anastomosis time clearly indicated that the RPT was simpler and easier to perform than the TOT or PST. During the anastomosis procedure of the RPT, a small incision was made to allow for the introduction of the anvil into the esophageal lumen. The operation is easier than in the TOT. In the latter operation, the anvil was transorally introduced by guidance of an orogastric tube, and was performed by an anesthesiologist in cooperation with the surgeon. The penetration of the stitch, suture, and anvil rod in the RPT made the positions of the esophagus and anvil more fixed, thus avoiding excessive surgery and unnecessary esophageal injury. The demanding operation of purse-string hand sewing under endoscopy was avoided in the RPT, and was instead 
achieved by cutting and closure of a linear stapler. This modification made the operation easier and the cutting edge more regular. Moreover, we can speculate that the less demanding operation of the RPT may greatly shorten the learning curve of surgeons.

Anastomosis leakage is the most serious complication post esophagectomy. The rate of anastomosis leakage in this study was $7.91 \%$, which is slightly higher than the pooled anastomosis leakage rate of $7.1 \%$ among 1,791 cases receiving stapler anastomosis for MIE (22) or 6\% among 700 cases who received circular stapler anastomosis for MIE reported by Yang et al. (23). This inconsistency may be attributed to the diverse definitions used for anastomotic leakage after esophagectomy and the different surgeons performing the surgery in different studies. The standardized definitions for anastomosis leakage proposed by the ECCG (18) were adopted in our study and hopefully may standardize the anastomosis leakage definition in future studies. However, the major leakage rate in this study was $1.90 \%$, which was slightly lower than the leakage rate of $5.7 \%$ requiring treatment after intrathoracic mechanical esophagogastric anastomosis in the study by Harustiak et al. (19).

Both minor and major leakage rates in the RPT, TOT, and PST groups were not significantly different. The multivariate analysis in our study revealed that the factors of tumor location, and neoadjuvant therapy rather than the methods of anvil placement may predict anastomotic leakage. This result was consistent with most previous studies, which suggested that anastomotic leakage may not be affected by the methods of anvil placement $(22,23)$. Minor leakage was speculated to be affected mainly by the sewing skills of surgeons during manual anastomosis (19). In this study, the anastomosis was generated by a mechanical circular stapler, so the concerns regarding sewing skills can be ignored in the comparison among circular stapler anastomosis techniques. One factor that may increase anastomosis leakage after using the RPT is that the end-to-end anastomosis may cross the linear stapler line, potentially increasing the risk of anastomosis leakage. However, according to the analysis results, the anastomosis leakage rate in the RPT group was not increased but slightly lessened compared with the other groups, so this concern is also unnecessary. On the other hand, major leakage might be associated with tissue ischemia that occurs after altered blood perfusion. Therefore, major leakage may not be affected by the methods of anvil placement but by surgical skills and some systemic or intrinsic factors that may influence blood perfusion, such as esophageal separation location, stomach stretching, or diabetes $(24,25)$. Our findings by multivariate analysis confirmed this presumption that the method of anvil placement is not a risk factor of anastomotic leakage.

Anastomosis stricture is a common long-term complication and seriously reduces the quality of life of patients. The rate of anastomotic stricture was $15.51 \%$ in our study, comparable with $13.6 \%$ reported by Tanaka et al. (26). The results of our study showed no difference with respect to anastomotic stricture between the experimental groups. Furthermore, the multivariate analysis revealed that the factors which may influence the development of anastomotic stricture included BMI, smoking history, and conversion rather than placement of the anvil. According to a previous study, the surgical factors associated with anastomotic stricture after esophagectomy may include small size of the anastomotic stapler, endto-end anastomosis, excessive tension at the anastomosis, and local tissue pressing, among other factors (27). These results and our study suggest that these 3 methods of anvil placement might not be influencing factors for stricture.

The other anastomotic complication rates did not significantly differ between the RPT, TOT, and PST groups. Overall, these results indicated that using the RTP would not increase the risk of anastomosis-related complications; thus, it is as safe and feasible as TOT or PST.

Besides simplicity, easier operation, safety, and feasibility, the RPT may also have the following advantages in clinical application: (I) in the RPT, the technique can be applied after a small modification of the anvil. In the Orvil technique, a specific Orvil circular stapler and transoral anvil introduction tube are needed; thus, RPT is more economical than the Orvil method; (II) during the anastomosis procedure, involvement of excessive or inadequate esophageal tissues is bad for anastomosis and may cause leakage. Cases of esophageal dilation may be difficult for the PST, as the involvement of the whole circle of the esophageal stump will create redundant esophageal tissue rolled in anastomotic doughnuts, which makes the anastomosis less secure. In the RPT, only part of the stump is involved in anastomosis, so the anastomosis formation will be less influenced by the excessive esophageal tissues. Therefore, in this situation, the RPT has obvious superiority (5). Previously, one limitation of the RPT was that the RPT requires adequate length of normal esophageal tissue. In the RPT, the esophageal wall penetration site is $2 \mathrm{~cm}$ or more above the esophageal incision and the esophageal incision is $3 \mathrm{~cm}$ or more above the tumor 
margin. Thus, the anastomosis site is $5 \mathrm{~cm}$ or more from the tumor. However, using a flexible curved intraluminal stapler makes the RTP still applicable in cases of tumors in much higher locations.

This is the first study comparing the RPT with two other methods of anvil placement in ILMIE. However, the inherent limitation of the retrospective study design suggests that the patient demographics and baseline clinical parameters were not well balanced. In the future, welldesigned randomized trials are warranted for further comparisons.

\section{Conclusions}

Compared with the TOT and PST methods of anvil placement for intrathoracic gastroesophageal circular stapling in ILMIE, the RPT method does not increase the risk of anastomotic leakage and stricture, but involves significantly shorter surgical time and anastomosis time. Therefore, the RPT method is a safe, effective, and easierto-perform anastomotic technique, worthy of further application and popularization in ILMIE.

\section{Acknowledgments}

Funding: This study was funded by a grant from the Zhejiang Provincial Natural Science Foundation (grant number: LQ17H010002).

\section{Footnote}

Reporting Checklist: The authors have completed the STROBE reporting checklist. Available at https://dx.doi. org/10.21037/jgo-21-322

Data Sharing Statement: Available at https://dx.doi. org/10.21037/jgo-21-322

Conflicts of Interest: All authors have completed the ICMJE uniform disclosure form (available at https://dx.doi. org/10.21037/jgo-21-322). The authors have no conflicts of interest to declare.

Ethical Statement: The authors are accountable for all aspects of the work in ensuring that questions related to the accuracy or integrity of any part of the work are appropriately investigated and resolved. This study was performed in accordance with the principles of the
Declaration of Helsinki (as revised in 2013). This research project was approved by the Ethics Committee of the 2nd Affiliated Hospital, School of Medicine, Zhejiang University with approval number 2021-0802. Due to the retrospective design of the study, the local ethics committee confirmed that informed consent was not necessary from participants.

Open Access Statement: This is an Open Access article distributed in accordance with the Creative Commons Attribution-NonCommercial-NoDerivs 4.0 International License (CC BY-NC-ND 4.0), which permits the noncommercial replication and distribution of the article with the strict proviso that no changes or edits are made and the original work is properly cited (including links to both the formal publication through the relevant DOI and the license). See: https://creativecommons.org/licenses/by-nc-nd/4.0/.

\section{References}

1. Stilidi I, Davydov M, Bokhyan V, et al. Subtotal esophagectomy with extended 2-field lymph node dissection for thoracic esophageal cancer. Eur J Cardiothorac Surg 2003;23:415-20.

2. Biere SS, van Berge Henegouwen MI, Maas KW, et al. Minimally invasive versus open oesophagectomy for patients with oesophageal cancer: a multicentre, open-label, randomised controlled trial. Lancet 2012;379:1887-92.

3. Luketich JD, Pennathur A, Awais O, et al. Outcomes after minimally invasive esophagectomy: review of over 1000 patients. Ann Surg 2012;256:95-103.

4. Blackmon SH, Correa AM, Wynn B, et al. Propensitymatched analysis of three techniques for intrathoracic esophagogastric anastomosis. Ann Thorac Surg 2007;83:1805-13, discussion 1813.

5. Pan S, Shen G, Wu M. Usage of "Reversal Penetrating Technique" with Ancillary Trocar in Minimally Invasive Ivor Lewis Esophagectomy. J Laparoendosc Adv Surg Tech A 2017;27:67-70.

6. Xiao P, Zhuang X, Shen Y, et al. Reverse-Puncture Anastomotic Technique for Minimally Invasive Ivor-Lewis Esophagectomy. Ann Thorac Surg 2015;100:2372-5.

7. Zhang H, Chen L, Geng Y, et al. Modified anastomotic technique for thoracolaparoscopic Ivor-Lewis esophagectomy: earlyoutcomes and technical details. Dis Esophagus 2017;30:1-5.

8. Atkins BZ, Shah AS, Hutcheson KA, et al. Reducing hospital morbidity and mortality following esophagectomy. Ann Thorac Surg 2004;78:1170-6; discussion 1170-6. 
9. Rindani R, Martin CJ, Cox MR. Transhiatal versus IvorLewis oesophagectomy: is there a difference? Aust N Z J Surg 1999;69:187-94.

10. Heits N, Bernsmeier A, Reichert B, et al. Long-term quality of life after endovac-therapy in anastomotic leakages after esophagectomy. J Thorac Dis 2018;10:228-40.

11. Cooke DT, Lin GC, Lau CL, et al. Analysis of cervical esophagogastric anastomotic leaks after transhiatal esophagectomy: risk factors, presentation and detection. Ann Thorac Surg 2009;88:177-84.

12. Rice TW, Gress DM, Patil DT, et al. Cancer of the esophagus and esophagogastric junction-Major changes in the American Joint Committee on Cancer eighth edition cancer staging manual. CA Cancer J Clin 2017;67:304-17.

13. Wang Q, Wu Z, Zhan T, et al. Comparison of minimally invasive Ivor Lewis esophagectomy and left transthoracic esophagectomy in esophageal squamous cell carcinoma patients: a propensity score-matched analysis. BMC Cancer 2019; 19:500.

14. Laxa BU, Harold KL, Jaroszewski DE. Minimally Invasive Esophagectomy: Esophagogastric Anastomosis Using the Transoral Orvil for the End-to-Side Ivor-Lewis Technique. Innovations (Phila) 2009;4:319-25.

15. Kang N, Zhang R, Ge W, et al. Major complications of minimally invasive Ivor Lewis oesophagectomy using the purse string-stapled anastomotic technique in 215 patients with oesophageal carcinoma. Interact CardioVasc Thorac Surg 2018;27:708-13.

16. Zhang RQ, Xia WL, Kang NN, et al. Pursestring stapled anastomotic technique for minimally invasive Ivor Lewis esophagectomy. Ann Thorac Surg 2012;94:2133-5.

17. Shen G, Pan SB, Wu M, et al. Use of efficient purse-string stapling technique for esophagogastric anastomosis in minimally invasive Ivor Lewis esophagectomy. J Thorac Dis 2013;5:898-901.

18. Low DE, Alderson D, Cecconello I, et al. International Consensus on Standardization of Data Collection for Complications Associated With Esophagectomy:

Cite this article as: Zhang B, Wu Z, Wang Q, Pan S, Wang L, Shen G, Chai H, Wu M. The comparisons of three stapler placement methods for intrathoracic mechanistic circular stapling in Ivor Lewis minimally invasive esophagectomy. J Gastrointest Oncol 2021;12(5):1973-1984. doi: 10.21037/jgo-21322
Esophagectomy Complications Consensus Group (ECCG). Ann Surg 2015;262:286-94.

19. Harustiak T, Pazdro A, Snajdauf M, et al. Anastomotic leak and stricture after hand-sewn versus linear-stapled intrathoracic oesophagogastric anastomosis: single-centre analysis of 415 oesophagectomies. Eur J Cardiothorac Surg 2016;49:1650-9.

20. Stoller JL, Samer KJ, Toppin DI, et al. Carcinoma of the esophagus: a new proposal for the evaluation of treatment. Can J Surg 1977;20:454-9.

21. Shen X, Chen T, Shi X, et al. Modified reverse-puncture anastomotic technique vs. traditional technique for total minimally invasive Ivor-Lewis esophagectomy. World J Surg Oncol 2020;18:325.

22. Zhou C, Ma G, Li X, et al. Is minimally invasive esophagectomy effective for preventing anastomotic leakages after esophagectomy for cancer A systematic review and meta-analysis. World J Surg Oncol 2015;13:269.

23. Yang L, Zheng Y, Jiang J, et al. Comparison of hand-sewn and stapled esophagogastric anastomoses: A meta-analysis. The Journal of Evidence-Based Medicine 2013;13:175-9.

24. Murphy CC, Incalcaterra JR, Albright HW, et al. Pretreatment patient comorbidity and tobacco use increase cost and risk of postoperative complications after esophagectomy at a high-volume cancer center. J Oncol Pract 2013;9:233-9.

25. Kassis ES, Kosinski AS, Ross P Jr, et al. Predictors of anastomotic leak after esophagectomy: an analysis of the Society of Thoracic Surgeons General Thoracic Database. Ann Thorac Surg 2013;96:1919-26.

26. Tanaka K, Makino T, Yamasaki M, et al. An analysis of the risk factors of anastomotic stricture after esophagectomy. Surg Today 2018;48:449-54.

27. Zhong S, Wu W, Sun S, et al. Risk factors of benign anastomostic stricture after esophagectomy with cervical reconstruction. Zhonghua Wei Chang Wai Ke Za Zhi 2014;17:877-80. 